\title{
Can I Have a Word Please - Strategies to Enhance Understanding of Subject Specific Language in Chemistry by International and Non-traditional Students
}

\section{Simon Rees, Megan Bruce \& Sam Nolan}

The Foundation Centre, Durham University, UK

\section{Corresponding author:}

Simon Rees, The Foundation Centre, Durham University, UK Email: simon.rees@durham.ac.uk

\begin{abstract}
In this paper we discuss the outcomes of our research into effective teaching strategies to enhance understanding of subject specific language by international and non-traditional students. Teaching strategies with an emphasis on improving scientific literacy were trialled over the course of the academic year 2010/11 in foundation level chemistry. The outcomes from this research led to the development of an E-glossary to support the development of subject language understanding. The E-glossary was trialled over the academic year 2011/12. It consists of student generated content (with over 100 contributions) explaining scientific terms and concepts in a variety of ways at an appropriate level for foundation students. The outcomes of this research are considered in relation to the development of scientific literacy and conceptual understanding.
\end{abstract}

Keywords: scientific language, glossary, learning styles, non-traditional students

\section{Introduction}

Durham University's Foundation Centre provides the opportunity for international and non-traditional students (e.g. mature students or those with few formal qualifications) to progress to a degree course at the University. There are about 200 students in 
the Foundation Centre working towards degree programmes throughout all departments within the University every year. Consequently, classes are very diverse and include students who have a wide range of previous experience and knowledge. A significant number of students advance to study subjects that require a good understanding of chemistry, for example, medicine, biomedical sciences, biology and, of course, chemistry itself. The technical and conceptual language needed to develop understanding in chemistry can pose particularly significant challenges to students.

Central to Vygotsky's theory of learning as a social construct is the language used by learner and teacher. As Vygotsky (1978) states, "when a child uses words he or she is helped to develop concepts. Language development and conceptual development are inextricably linked. Thought requires language, language requires thought". The challenges of inducting students into the community of practice for their chosen discipline are widely recognised and lack of familiarity with discipline specific terminology can be a significant barrier for them (Freedman 1987). Similarities are often drawn between learning the language of science and a foreign language (e.g. Rincke 2010) because, to be successful, students have to comprehend and make use of a new and developing vocabulary in order to communicate within the subject area. In addition, everyday words may be used in particular and precise ways in chemistry. These challenges may be even more significant in the Foundation Centre context as students will arrive with previously constructed (mis)understandings of terminology and its usage, as illustrated in this extract from a student email:

"Sorry to bother you over the holidays but...... think I am being a bit thick but I just do not understand the use or meaning of The Avogadro Constant. Is this only applicable to carbon 12 ? why is it carbon- 12 and not another element? Is this a formula $i$ should use to find the weighted mass of other atoms? Could i not just use the formula Mole $=$ Grams $/$ RAM to find the weighted mass of an atom or molecule instead?"

Here the student is struggling to understand the meaning of the central term 'Avogadro's Constant' and in so doing is using at least nine other subject specific terms (e.g. carbon 12, molecule etc.) to try to engage in a discussion of its meaning. These other terms are referred to as "protagonists" (Ogborn et al. 1996); they are other subject specific terms of which a student requires a secure comprehension in order to develop their understanding of the central term. Here understanding of these aspects is clearly confused as the student has combined aspects of definitions of other related terms such as Relative Atomic Mass and has created the term weighted mass (which should be weighted mean mass).

There has been some debate over the last decade as to the best way to define vocabulary in academic contexts. Coxhead (2000) developed the Academic Word List (AWL) which consists of 570 word families that students need to know in order to pursue any degree programme in English. The AWL was based on a corpus of 3.5 million words of written academic discourse drawn from 28 subject areas. Nation (2001) divides vocabulary into three main groups: high frequency words (covering over $80 \%$ of most texts), general academic vocabulary (about $10 \%$ of academic texts) and technical vocabulary (covering up to $5 \%$ of academic texts). Following on from Coxhead's Academic Word List (AWL) (Coxhead 2000), Hyland \& Tse (2007) suggested that there may not, in fact, be a general academic vocabulary, but rather that words which had been thought to be cross-disciplinary in academic writing (such as process, analyse, etc) are in fact used differently according to discipline. The E-glossary focuses primarily on technical vocabulary, but also includes some rudimentary activities that give students more general vocabulary building skills, for example by using etymological roots to guess at word meanings. There are also activities that support students' reading skills by showing them how they can understand the meaning of a text without knowing all the vocabulary items it contains. Although this does not cover all possibilities of lack of comprehension or misconstruing of meaning, such strategies can broadly support the making of meaning. It is our aim, through this research, to provide the students with the best possible learning experience to enable them to construct a clear understanding of the meaning of the terms so that they can develop the strategies to undertake subject specific discourse with confidence as they progress through their degree programmes.

\section{Methodology}

\section{Classroom strategies}

Over the course of the academic years 2010/11 and $2011 / 12$ a variety of different teaching strategies was employed in the classroom setting which focused on developing understanding of subject specific vocabulary. The range of activities included:

- Modelling activities, for example the use of play dough to construct atoms and bonding between atoms. 
- Word games, for example guess the word, picture charades and 'pass the bomb'.

- Glossaries, for example first and second attempt glossaries (where students are provided with a list of relevant words at the start of a topic and then the process is repeated at the end to see how their explanations have developed).

- Comprehension style activities, for example Directed Activities Related to Text (DARTS). See Wellington and Osbourne (2001) for a comprehensive discussion.

\section{Review - stage 1}

The impact of the strategies was reviewed using class questionnaires and focus groups.

\section{E-glossary}

The outcomes from the stage 1 review led to the development of an online E-glossary (www.dur.ac. uk/foundation.science) for students to contribute their own definitions of key words. For example, one mature learner who was running a corner shop whilst undertaking her studies commented:

"When there are no customers in I spend lots of time on Google looking at chemistry things".

In one sense it is encouraging that the student is engaged in the course and spends significant amounts of time outside of lessons trying to develop their understanding. However, how appropriate and relevant to the student's course of study the content access is, is also of considerable concern. If the material accessed is inappropriate, the result for the student can be confusion, misconceptions and less progress. This is particularly true for a student who is returning to study after many years and has yet to develop the critical evaluation skills required to assess the relevance of the information obtained. The E-glossary was conceived as a means of providing course students with the most appropriate and relevant web resources.

\section{Principles of the E-glossary:}

- It is a dedicated subject and course specific resource to ensure that the examples and explanations are appropriate to students studying foundation level chemistry.

- The content is sourced and uploaded by students on the course with moderation by the course leader.

- There should be a variety of explanations, for example video, podcast, animations, different languages and so on, to appeal to different people with different individual learning styles.
The E-glossary is hosted on a set of web pages which exist outside the university's VLE. These pages use the Drupal Content Management System (CMS). This was done to facilitate greater tracking of student use and to make the website accessible as an Open Educational Resource (OER). Each entry to the E-glossary is given its own distinct blog page. A summer student, Andy Castillo-Dubuc, was employed to create a set of sample entries for students to look at. Staff and students were then given personal accounts that allow them to add to blog pages and create new entries in the E-glossary. In addition, students and staff have the ability to post comments on entries, which could be of the form "a better resource is X", or "I don't understand $Y$ as defined here could you clarify". The E-glossary was launched at the beginning of the 2011/12 academic year and utilised throughout the course.

\section{Review - stage 2}

The benefits of the E-glossary were reviewed using class questionnaires and focus groups.

\section{Results}

\section{Review - stage 1}

The students were asked the following question in relation to the trialled teaching strategies:

1. For each of the following teaching strategies please evaluate their usefulness for developing your understanding of key scientific terms.

(if you have no experience of a strategy then leave it blank)

The overall response from the questionnaires indicated that the students appreciated a variety of approaches. There was wide variety in the responses from the students as shown by the standard deviation. This reflects the fact that different students had different preferences.

Comments in favour of certain strategies included:

Modelling

"I find it easier to learn when I visualise things"

\section{Analogies}

"It's every day experience so it tends to stick in my brain easily"

"It can be explained without using unknown terms and doesn't confuse as much" 
Examples to show the term in context

Glossaries to record definitions of new terms

Modelling (e.g. the use of modelling kits to construct organic molecules.

Visual aids (e.g. diagrams/animations/video)

Analogies (i.e. relating a process to human experience such as collision theory in atoms like bumping into someone in the street)

Role play (i.e. where you participate in activities to explain a term or concept such as modelling movement of ions and electrons in an electrochemical cell)

Word games (e.g. picture charades)

Card sorting/definition matching exercises

Practical experiments

Other (please specify)

\section{Glossaries}

"Can be referred back to and used in many contexts"

\section{Visual aids}

"Allow me to see and think about things that the human eye cannot see"

Word games received the lowest score out of the different strategies, with some more negative comments such as:

"I just couldn't see the point in them"

\section{Review - Stage 2}

By the end of the academic year 2011/12 there had been 102 contributions by students to the E-glossary. Fifty of these contributions can be accounted for as those which the students were required to make as part of their assignments; the remaining 52 are, therefore, contributions made on a more voluntary basis.

Contributions ranged from one or two sentences explaining the meaning of a word to more extended and detailed explanations. Students also uploaded links to other resources such as video clips, animations and online exercises.

Examples of some interesting entries include:

\section{Collision theory}

"A good way to understand what is happening is to use a 'thought experiment' imagine a football pitch with 22 players each one dribbling a ball around the pitch with their heads down (at random).
Some players dribble faster than others and some dribble slower but there is an average speed that most player go at.

Some players will collide and some will lose control of the ball (collisions with energy greater than the activation energy) and some will not (collisions with energy lower than the activation energy).

But because there is a lot of space these collisions are infrequent.

Now add 22 more players and the chances of a collision become more frequent again some losing control and some not, but because the total frequency of collisions has increased so will the collisions involving a loss of control (a chemical reaction).

As you can see if you add another 22 players these collisions will increase and so on."

Cation

"Cations are PUSS-itive!"

Acid

MASH - Metal + Acid $\rightarrow$ Salt + Hydrogen

Useful resources were sourced by the students, who were able to share them readily with the rest of the class. The resources can also be incorporated into lessons by the teacher in to lessons.

Feedback from focus group discussions raised several interesting ideas.

The students pointed out that in order to encourage contributions to the glossary the following factors were important:

- it should be as easy as possible to make an entry, and clickage should be reduced to a minimum, for example by removing the need to log in to review the comments page; 
- its use should be incorporated as much as possible within the course, for example by including it in the summative assignment and by referring to entries in class to promote it in the students' consciousness.

It was also suggested that the 'textbook' definition of a word should be given first and then the variety of student contributions would follow on. The principle of the glossary, however, is not to provide short definitions of words, but rather to gather different examples of the scientific use of a word to demonstrate and explain the range of its applications in different contexts as proposed by other researchers (Ogborn et al. 1996, Rincke 2010).

\section{Discussion}

Bryson \& Hand (2007) state that the research evidence is clear that the approaches a teacher takes can have a positive influence on the quality of learning. In this study we have identified a variety of strategies that students found useful to assist in the development of their understanding of key chemistry terms. The most significant point that is apparent from the student feedback is the importance of variety. Some people preferred opportunities to make atomic models and work out how bonds were formed, whilst others preferred the use of analogies. This supports the ideas related to preferred learning styles and also research demonstrating that teaching innovations designed to improve student learning appear to change or improve the learning of some students, but are by no means guaranteed to work with all students (Vermetten et al. 2002). It would be interesting to explore these ideas further in relation to international and non-traditional students in terms of the most effective teaching strategies for them and the extent to which they experience these as they progress through their degree programmes.

Several of the teaching strategies, such as the first and second attempt glossaries and the E-glossary operate within the constructivist theory of learning whereby learners develop a personal representation of knowledge. A good example of this is the football collision theory analogy posted by one student on the E-glossary. This demonstrates the student constructing their own personal representation of the meaning of the term 'collision theory' and of the underlying concept. Previously, a student may have conceived of such an idea when writing an assignment, but it is now possible to share this with other students on the course via the E-glossary, and thereby encourage them to develop their own ideas. The salience of the individual perception of the student is important (Entwistle 1991), and it is the teacher's role to facilitate the construction of student's ideas about the subject. November \& Day (2012) identified the difficulties students have in accessing their courses because of the subject terminology, and describe the use of a student driven E-glossary for courses in health and in music for which the students were required to write a 200 word entry defining a term on the glossary. They conclude that it was successful in encouraging the students to

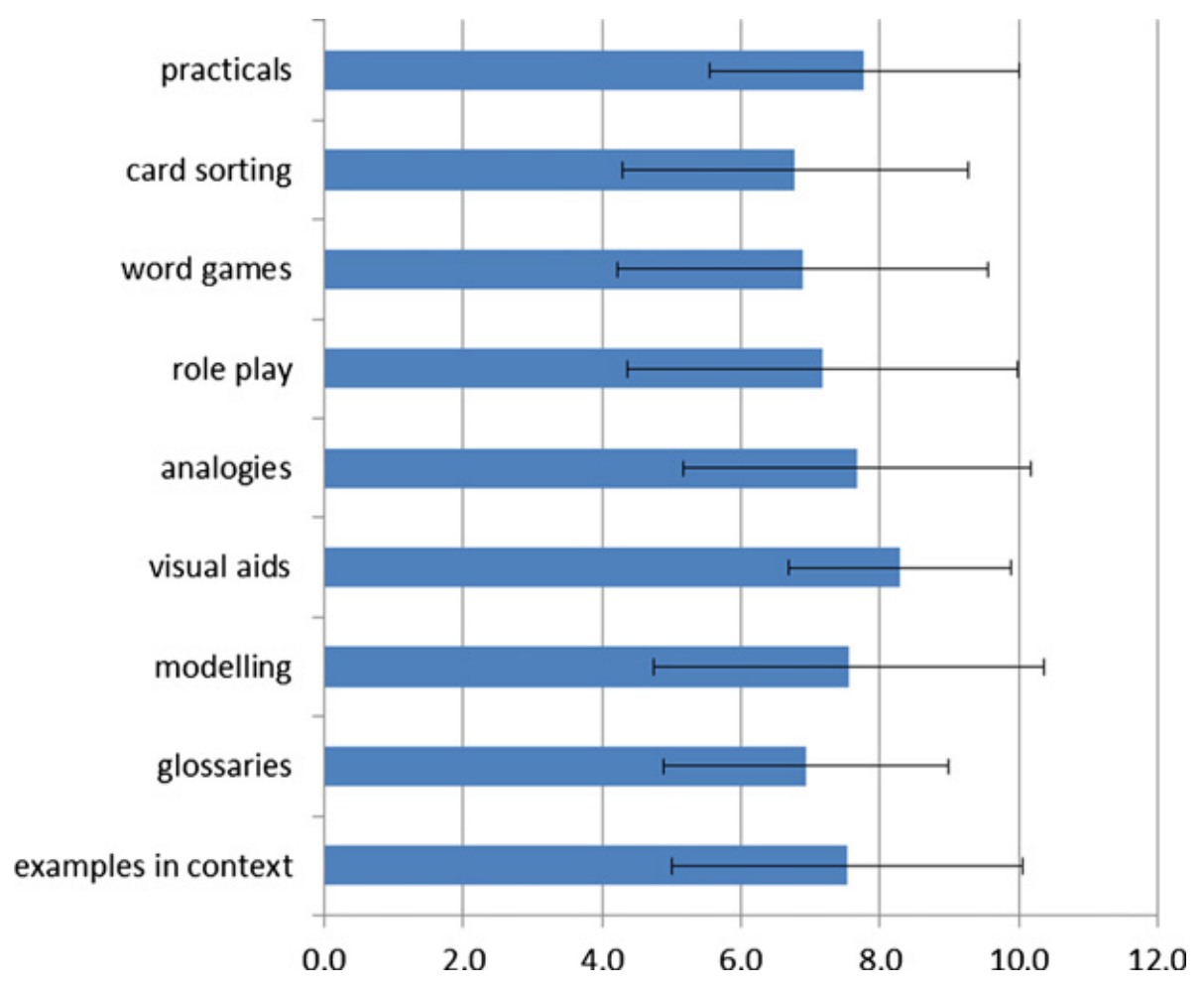

Figure 1 Mean student responses to Q1 $(n=35)$ with standard deviation. 
research their chosen word and associated terms more thoroughly and broadened their knowledge.

The E-glossary we have developed has provided a mechanism for students to make contributions to the course and share these with others. It has contributed to improving student engagement with the course, and has enabled these students to commence their journey from a surface to a deeper approach to learning, something widely recognised as desirable for improved student learning to take place (e.g. Biggs 1999). The process encourages students to develop autonomous learning skills, and to reflect on the relevance of the information they obtain. The extent to which a learner can develop independent thought and take more responsibility for their own learning is commonly associated with 'higher' levels of learning (Martin 1999); this is significant as these students make the transition to H.E. and develop the study skills that will be required as they progress.

\section{Conclusion}

The teaching strategies described in this paper were found to stimulate student interaction and increase their opportunities to construct meanings for chemistry terms. The E-glossary concept has the advantage of being readily adaptable and capable of responding to unanticipated needs and student feedback. We aim to take this work further by exploring the application of linguistic teaching strategies to the course (including the development of a corpus of chemistry student texts), and to develop exercises to assess levels of student literacy upon course entry, and then to track the development in student understanding of subject specific language in chemistry.

\section{Acknowledgements}

The E-glossary was developed with assistance of Foundation Centre student Andy Castillo-Dubuc, who was supported by a Durham University Enhancing Student Experience Award.

\section{References}

Biggs, J. (1999) Teaching for quality learning at University. Buckingham: Society for Research into Higher Education and Open University Press.

Bryson, C. and Hand, L. (2007) The role of engagement in inspiring teaching and learning, Innovations in Education and Teaching International 44 (4), 349-362.

Coxhead, A. (2000) A new academic word list. TESOL Quarterly 34, 213-238.

Entwistle, N. (1991) Approaches to learning and perceptions of the learning environment Introduction to the special issue. Higher Education 22, 201-204.

Freedman, A. (1987). Learning to write again: discipline specific writing at university. Carelton Papers in Applied Language Studies 4, 45-65.

Hyland, K. and Tse, P. (2007). Is there an "Academic Vocabulary"? TESOL Quarterly 41 (2), 235-253.

Martin, E. (1999) Learning and Teaching in Higher Education. Buckingham: Society for Research into Higher Education and Open University Press.

Nation, I.S.P. (2001) Learning Vocabulary in Another Language. New York: Cambridge University Press.
November, N. and Day, D. (2012) Using undergraduates' digital literacy skills to improve their discipline-specific writing: a dialogue. International Journal for the Scholarship of Teaching and Learning 6 (2), 1-21.

Ogborn, J., Kress, G., Martins, I. and McGillicuddy, K. (1996) Explaining Science in the Classroom.

Buckingham: Open University Press.

Rincke, K. (2010) It's rather like learning a language: development of talk and conceptual understanding in mechanics lessons. International Journal of Science Education 33 (2), 229-258.

Vermetten, Y.J., Vermunt, J.D. and Lodewijks, H.G. (2002) Powerful learning environments? How university students differ in their response to instructional measures. Learning and Instruction 12 (3), 263-284.

Vygotsky, L.S. (1978) Mind and Society: The Development of Higher Mental Processes. Cambridge, MA: Harvard University Press.

Wellington, J. and Osbourne, J. (2001) Language and Literacy in Science Education. Buckingham: Open University Press. 